\title{
Indications and Use of Hydrogen Peroxide during Microvascular Flap Reconstruction Surgery: A Literature and Procedural Use Review
}

\author{
E. Rodriguez-Collazo, DPM ${ }^{1}$ \\ D. Riddle, DPM, DC, MPH² \\ ${ }^{1}$ Department of Surgery, Chicago Foot and Ankle Deformity \\ Corrections Center, Presence Saint Joseph Hospital, Chicago, Illinois \\ 2 Section of Podiatric Surgery, Department of Surgery, Presence Saint \\ Joseph Hospital, Chicago, Illinois
}

K. Schmidtke, DPM ${ }^{2}$

\author{
Address for correspondence K. Schmidtke, DPM, Section of Podiatric \\ Surgery, Department of Surgery, Presence Saint Joseph Hospital, \\ 2900 North Lake Shore Drive, Chicago, IL 60657 \\ (e-mail: sjhkevin.schmidtke@gmail.com).
}

J Reconstr Microsurg Open 2017;2:e23-e25.

\begin{abstract}
Keywords

- hydrogen peroxide

- hemostasis

- embolization

Microvascular flap reconstruction surgery is a limb preservation procedure performed in an effort to maintain the integrity of the lower limb and avoid amputations. Individuals facing the prospect of amputation often have long-term diabetes with multiple comorbidities, including severe peripheral vascular disease; peripheral arterial disease; chronic ulcerations; and Charcot arthropathy. Long-term clinical research has shown that these patients are at much higher risk for secondary amputations after a first amputation is performed. According to Sohn et al, Charcot and ulcer groups had 4.1 and 4.7 amputations per 100 person-years, respectively. In patients younger than 65 years old at the end of follow-up, amputation risk, relative to patients with Charcot alone, was 7 times higher for patients with ulcer alone and 12 times higher for patients with Charcot and ulcer. Patients with infected hardware, suffering from acute ulcerative conditions, may also be candidates for this type of surgery due to extensive tissue loss secondary to infection. Microvascular flap reconstruction surgery is a highly technical surgery involving the use of orthoplastic techniques, which is performed under $\times 3.5$ loupe magnification. Due to the inability to perform this procedure with the use of a tourniquet, visibility within the field is obfuscated from continuous blood flow along the dissected muscle belly. Hydrogen peroxide $\left(\mathrm{H}_{2} \mathrm{O}_{2}\right)$ is an excellent alternative to tourniquet use. The use of $\mathrm{H}_{2} \mathrm{O}_{2}$ allows additional benefits, such as visual field clearance and antisepsis.
\end{abstract}

This literature and case review is prepared in an effort to determine the efficacy, indications, and contraindications of using a $3 \%$ hydrogen peroxide $\left(\mathrm{H}_{2} \mathrm{O}_{2}\right)$ solution during this procedure. The use of $\mathrm{H}_{2} \mathrm{O}_{2}$ in open dissection can be found throughout recent literature, in various medical disciplines. Literature review is limited to post-1980 and will address three topics; visual field clearance, topical antiseptic, and hemostasis. ${ }^{1}$

received

November 3, 2016 accepted after revision January 7, 2017
DOI http://dx.doi.org/ 10.1055/s-0037-1601326. ISSN 2377-0813.
$\mathrm{H}_{2} \mathrm{O}_{2}$ was first described in 1818 by Louis Jacques Thenard, but pure $\mathrm{H}_{2} \mathrm{O}_{2}$ was not synthesized until $1894 . \mathrm{H}_{2} \mathrm{O}_{2}$ has been used throughout history as a disinfectant and for antisepsis based on solution strength. This solution is an important endogenous structure in phagocytosis in the immune system. $\mathrm{H}_{2} \mathrm{O}_{2}$ has harmful characteristics at higher concentrations and is considered unsafe for topical use over $6 \%{ }^{2}$ The solution's vapors are used for sterilization of

Copyright $\odot 2017$ by Thieme Medical Publishers, Inc., Inc., 333 Seventh Avenue, New York, NY 10001, USA Tel: +1(212) 584-4662.
License terms

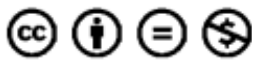


surgical instruments. Solutions of $3 \%$ are sold over the counter and used as an antiseptic. $\mathrm{H}_{2} \mathrm{O}_{2}$ demonstrates broad-spectrum efficacy against viruses, bacteria, yeasts, and bacterial spores.

The ability for catalase to break down $\mathrm{H}_{2} \mathrm{O}_{2}$ into a foaming agent and create microembolisms in the vasculature can be used to the surgeon's advantage during microvascular flap reconstruction surgery. The breakdown of $\mathrm{H}_{2} \mathrm{O}_{2}$ into oxygen gas and water allows for increased visibility through dilution. In addition, the ability for $\mathrm{H}_{2} \mathrm{O}_{2}$ to act on a clot as a dissolution agent may increase the viability of muscle cells during the procedure. Excessive clotting during a long, extensive procedure allows for unwanted muscle hypoxia. Although there is abundant literature concerning the risk of embolism when $\mathrm{H}_{2} \mathrm{O}_{2}$ is used as an irrigation agent in a closed space, this is mitigated due to the open dissection used during this procedure.

\section{Literature Review}

\section{Visual Field Clearance}

Wu et $\mathrm{al}^{3}$ conducted a study in which 20 patients with acute upper gastrointestinal bleeding (13 males and 7 females) were included. The site of bleeding was sprayed with $200 \mathrm{~mL}$ of saline and again with 25 to $175 \mathrm{~mL}$ of $3 \% \mathrm{H}_{2} \mathrm{O}_{2}$. Pictures of the visual fields were taken and compared by three gastroenterologists and graded on a visual scale. Cauterization of the bleeding field was performed and a biopsy was taken to evaluate the effects of the $\mathrm{H}_{2} \mathrm{O}_{2}$ on the area. The results showed a significant improvement in the mean visual score with $\mathrm{H}_{2} \mathrm{O}_{2}$ compared with saline alone. In addition, during endoscopic evaluation, 19 patients were seen to have active oozing from an adherent blood clot at the ulcer base. Altogether 12 of these individuals achieved initial hemostasis after being sprayed with $3 \% \mathrm{H}_{2} \mathrm{O}_{2}$. Finally, there were no significant changes in the histology of the biopsied sites.

A second, similar study conducted by Kalloo et $\mathrm{al}^{4}$ at the John Hopkins University found similar results. In six patients with acute upper gastrointestinal bleeding, $\mathrm{H}_{2} \mathrm{O}_{2}$ spray resulted in good to excellent visualization of the bleeding source. Hemostasis occurred in two patients who were actively bleeding. There were no adverse effects or complications. The authors concluded that $\mathrm{H}_{2} \mathrm{O}_{2}$ significantly enhanced clot dissolution and endoscopic visualization in patients with acute upper gastrointestinal bleeding. This study differed from the previous study, by Wu et al, with the addition of an antifoaming agent, simethicone, being mixed with the $\mathrm{H}_{2} \mathrm{O}_{2}$. Simethicone decreases the surface tension of gas bubbles allowing them to combine into larger bubbles.

\section{Antisepsis}

$\mathrm{H}_{2} \mathrm{O}_{2}$ has long been known as a topical antiseptic due to the breakdown of bacterial cell walls due to the catalase reaction. According to Hyslop et al, a concentration of $500 \mathrm{mM}$ is needed to completely kill Staphylococcus aureus cells when exposed $^{5} ; 3 \% \mathrm{H}_{2} \mathrm{O}_{2}$ (980 mM) sufficiently succeeds this threshold. The authors concluded that levels of 25 to $50 \mathrm{mM}$ of $\mathrm{H}_{2} \mathrm{O}_{2}$ are bacteriostatic. There is a debate on whether this concentration of $\mathrm{H}_{2} \mathrm{O}_{2}$ is cytotoxic at longer duration of contact. There is no definitive answer to this question at this time. Consequently, these procedures are concluded with a wash of normal saline in an effort to decrease the incident, if any, of cytotoxicity to healthy tissue.

\section{Hemostasis}

There are two possible reactions in terms of hemostasis when $\mathrm{H}_{2} \mathrm{O}_{2}$ is used as an irrigation solution. First is the catalase reaction wherein $\mathrm{H}_{2} \mathrm{O}_{2}$ is broken down into water and oxygen gas: $2 \mathrm{H}_{2} \mathrm{O}_{2} \rightarrow 2 \mathrm{H}_{2} \mathrm{O}+\mathrm{O}_{2}$. Second is the Fenton reaction: $\mathrm{Fe}^{3+}+\mathrm{H}_{2} \mathrm{O}_{2} \rightarrow \mathrm{Fe}^{2+}+\mathrm{HOO} \cdot+\mathrm{H}^{+}$, where a free radical is created using iron from the hemoglobin as a catalyst.

Foaming is created with either reaction as gas by-products are released.

$\mathrm{H}_{2} \mathrm{O}_{2}$ injection has been shown to reduce blood loss during surgery by Lichtenbaum et al. ${ }^{6}$ Further studies involving this technique by Mastronardi and DeWaele ${ }^{7}$ revealed the creation of intraluminal bubbles from this reaction in mice. ${ }^{7}$ This has led many to caution the use of $\mathrm{H}_{2} \mathrm{O}_{2}$ in a closed space environment such as the spine, brain, or deep abscesses. This study highlighted the possibility of gas collection leading to embolism in close spaces.

It has been theorized that collection of these bubbles may act as a barrier through high surface tension on a low pressure capillary bed causing retention of blood flow, thus decreasing blood loss during surgery. Gas embolization is a concern in a closed space where the gas may have the ability to collect and travel in small vessels, leading to embolization. Morikawa et $\mathrm{al}^{8}$ described an embolism in their article concerning the use of $\mathrm{H}_{2} \mathrm{O}_{2}$ in cervical spinal surgery. Despite the transient nature of the embolization that occurred, they concluded that there is a concern for use of $\mathrm{H}_{2} \mathrm{O}_{2}$ in closed spaces. However, in the meningioma surgery study by Lichtenbaum et $\mathrm{al}^{6}$, they concluded that embolization did not occur in the spinal surgery. The differences in location are key to understanding the possibility of embolization. Cervical spinal surgery is a smaller field with deeper access than the surgery described herein. Spinal surgeries and the procedures described here are performed in an open field allowing the gas to dissipate, as well as having a wider field in which to remove any remaining $\mathrm{H}_{2} \mathrm{O}_{2}$. There is a possibility for the flap itself to experience a small amount of embolization along the periphery due to lingering presence of $\mathrm{H}_{2} \mathrm{O}_{2}$. The saline wash along with gentle palpation along the periphery of the flap during the wash ensures the remaining pockets to dissipate prior to implantation.

\section{Procedural Use of Hydrogen Peroxide}

At the beginning of each microvascular flap reconstructive case, a basin is filled with $120 \mathrm{~mL}$ of $\mathrm{H}_{2} \mathrm{O}_{2}$. A bulb syringe or a Luer lock $60 \mathrm{~mL}$ syringe is used to administer the $\mathrm{H}_{2} \mathrm{O}_{2}$ to the patient. The $\mathrm{H}_{2} \mathrm{O}_{2}$ is used intermittently throughout the case. No tourniquet is used.

After initial skin incision, 10 to $20 \mathrm{~mL}$ of $\mathrm{H}_{2} \mathrm{O}_{2}$ is used along with direct pressure. The $\mathrm{H}_{2} \mathrm{O}_{2}$ controls the smaller capillaries and allows the larger vessels to be more easily 
visualized for Bovie cauterization. After dissection through the subcutaneous fat to the level of the fascia, another application of $\mathrm{H}_{2} \mathrm{O}_{2}(5-10 \mathrm{~mL})$ is used, along with direct pressure. Subsequently, through the level of the fascia, another 5 to $10 \mathrm{~mL}$ of $\mathrm{H}_{2} \mathrm{O}_{2}$ and direct pressure is used to control any additional deep bleeding vessels. This stepwise procedure is constant for every case.

When performing a nerve repair case, additional $\mathrm{H}_{2} \mathrm{O}_{2}$ is used during dissection of the nerve from the surrounding tissue. When a minor segmental flap procedure is performed, $\mathrm{H}_{2} \mathrm{O}_{2}$ is used for the muscle flap dissection. A total of $20 \mathrm{~mL}$ of $\mathrm{H}_{2} \mathrm{O}_{2}$ is used in both cases. In total, approximately 60 to $70 \mathrm{~mL}$ of $\mathrm{H}_{2} \mathrm{O}_{2}$ is used. The average blood loss for a nerve repair case or a minor segmental muscle flap is 25 to $40 \mathrm{~mL}$. Total fluid collection including blood and $\mathrm{H}_{2} \mathrm{O}_{2}$ is 85 to $110 \mathrm{~mL}$.

For a large muscle flap with resection of tibia and fibula, an additional three to four applications of $\mathrm{H}_{2} \mathrm{O}_{2}$ are needed. In total, $120 \mathrm{~mL}$ of $\mathrm{H}_{2} \mathrm{O}_{2}$ is used in these larger procedures. Blood loss for a large muscle flap is in the range of $150 \mathrm{~mL}$ leading to a total fluid collection of 400 to $500 \mathrm{~mL}$. Normal saline is used at the completion of all procedures prior to closing.

\section{Conclusion}

In regard to the actions created through the use of $\mathrm{H}_{2} \mathrm{O}_{2}$ in an open field procedure, it may be possible that these two reactions are forming and reforming simultaneously, in regard to hemostasis. $\mathrm{H}_{2} \mathrm{O}_{2}$, when introduced exogenously in repeated washes, allow the following to occur:

1. Catalase reaction allows dilution of the hemoglobin in the visual field, increasing visibility.

2. The Fenton reaction taking place, wherein a free radical is formed, leading to the breakdown of the cell wall and to clot formation.

3. Catalase reaction may also act as disagglutination process on newly forming clots with subsequent washes.

4. Both reactions liberate gas, leading to microembolization of smaller vessels and capillary beds.

$\mathrm{H}_{2} \mathrm{O}_{2}$ and its effect on homeostasis is important when viewed in terms of reducing blood loss during these procedures. There is marked visual improvement in the surgical field. Blood loss is kept to a minimum and antisepsis is achieved throughout the procedure. A final wash with normal saline throughout the open field and along incision lines allows the surgeon to dilute any lingering $\mathrm{H}_{2} \mathrm{O}_{2}$. Dilution clears the capillary beds of cell breakdown debris and ensures that there are no pockets of $\mathrm{H}_{2} \mathrm{O}_{2}$ left against healthy cells during the healing process.

Understanding the biochemical pathways concerning platelet aggregation and breakdown, the chemical reactions that occur and the procedural details of when $\mathrm{H}_{2} \mathrm{O}_{2}$ is used will further the surgeon's ability to successfully minimize blood loss during an open field microvascular muscle flap procedure.

\section{Acknowledgments}

The authors would like to thank Dr. Andrew Lindekugel, DPM, for his editorial support. The authors have declared no potential conflict of interest.

\section{References}

1 Sohn MW, Stuck RM, Pinzur M, Lee TA, Budiman-Mak E. Lowerextremity amputation risk after Charcot arthropathy and diabetic foot ulcer. Diabetes Care 2010;33(01):98-100

2 Cheminfo. Hydrogen Peroxide Solutions of less than 8\%. 1998. Available at: ccinfoweb2.ccohs.ca/whmis/records/77E.html. Accessed September 2, 2016

3 Wu DC, Lu CY, Lu CH, et al. Endoscopic hydrogen peroxide spray may facilitate localization of the bleeding site in acute upper gastrointestinal bleeding. Endoscopy 1999;31(03):237-241

4 Kalloo AN, Canto MI, Wadwa KS, et al. Clinical usefulness of 3\% hydrogen peroxide in acute upper GI bleeding: a pilot study. Gastrointest Endosc 1999;49(4 Pt 1):518-521

5 Hyslop PA, Hinshaw DB, Scraufstatter IU, Cochrane CG, Kunz S, Vosbeck K. Hydrogen peroxide as a potent bacteriostatic antibiotic: implications for host defense. Free Radic Biol Med 1995; 19(01):31-37

6 Lichtenbaum R, de Souza AA, Jafar JJ. Intratumoral hydrogen peroxide injection during meningioma resection. Neurosurgery 2006;59(04, Suppl 2):ONS470-ONS473, discussion ONS473

7 Mastronardi L, DeWaele L. Intratumoural hydrogen peroxide injection during resection of metastatic vertebral melanoma. Technical note. Neurosurg Rev 2011;34(03):389-391, discussion 391

8 Morikawa H, Mima H, Fujita H, Mishima S. Oxygen embolism due to hydrogen peroxide irrigation during cervical spinal surgery. Can J Anaesth 1995;42(03):231-233 